\title{
Study on the Schedule Optimization and Control Methods for Scientific Research and Production Management in Aviation Enterprise
}

\author{
Wang Qingjun \\ Economics and Management Institute \\ Shenyang Aerospace University \\ Shenyang City, China \\ 32582669@qq.com
}

\author{
Wu Jingtai \\ Economics and Management Institute \\ Shenyang Aerospace University \\ Shenyang City, China
}

\begin{abstract}
Aviation technology, as an important sign for national development and progress, represents the national science and technology development level. Nowadays, the world is developing by leaps and bounds and various technologies are developing. The research \& development for aviation enterprise are attached great importance to, which cannot be ignored. In addition, the study on the schedule optimization and control methods for scientific research and production management in aviation enterprise will greatly improve the development, guarantee that it will be adapted to the trend of the world. Besides, the great functions shall be ignited to make contributions to the national development. This paper analyzes the scientific research and production management from the perspective of level production, informationization construction, and uncertainty quantification so as to have a deeper understanding of the schedule optimization and control methods for scientific research and production management in aviation enterprise.
\end{abstract}

Keywords-Aviation Enterprise; Scientific research and production Management; Quantification; Level Production; Informationization

\section{INTRODUCTION}

Nowadays, the society is developing fast and Chinese economy grows rapidly with a big boost in economic level. Meanwhile, the continuous change in terms of equipment procurement system leads to the serious damage of environment for aviation enterprises which ask more requirements. As the modern society develops rapidly, consumers have different changes in terms of product requirement and the product using cycle is constantly shortening. In addition, the technology is being constantly innovated and changed, which brings along with a more and more intensified competition. While facing different tasks and diverse tasks in different stages, aviation enterprises should ask higher requirements on themselves to optimize their scientific research and production management schedule so as to seek for more suitable control methods, change their direction and take the market as the orientation. At the same time, they should change the previous operating model to focus on cost controlling.

Concerning the scientific research and production management, the important aspects include schedule optimization and controlling. Only by guaranteeing the mutual progress of these two aspects can we greatly improve the progress and development of aviation enterprises because their development directly affects the research fee, quality and production cycle and meanwhile can guarantee that the scientific research can be completed in time with good quality, effectively control the cycle, cost, take good advantage of resources and realize optimal control. Moreover, the schedule optimization can guarantee that the scientific research and production management can be finished within the prescribed time with more suitable plans. Furthermore, concerning the plan implementation, we can carry out regular detection to find out differences and constantly optimize the management progress so that we can carefully analyze and comment on possible situation to further optimize the situation. In terms of different problems, we can adopt different methods to optimize to finally conclude a reasonable and scientific plan, which can perfectly adapt to requirements. Concerning the schedule optimization and control methods for scientific research and production management in aviation enterprises, this paper carries out analysis from the following perspectives.

\section{LEVEL PRODUCTION IN SCIENTIFIC RESEARCH AND PRODUCTION MANAGEMENT}

Level production is an important aspect for the scientific research and production management in aviation enterprises, which means during a relatively fixed period of time, the product quantity or increased products are average or full. Level production has a dazzling array of advantages for the scientific research and production management, which cannot only take comprehensive utilization of the human resources and equipment in aviation enterprises to minimize the risk of quality problem because of extra work and crashing work but also improve the optimization of the scientific research and 
production management in aviation enterprises. The adoption of level production does not only control and reduce the cost but also guarantee the product quality to achieve civilized and safe production. The following should be paid attention to so as to effectively apply level production to scientific research and production management.

A. Firstly, the relation among different types, infrastructure, and basic research as well as the relation between model research and advanced models

Concerning the relationship among different objects, we have to carry out a clear analysis and have a clear understanding. For different modes, we have to carry out comprehensive consideration. The research and development in aviation enterprises are carried out for different models. Therefore, we have to analyze the primary and secondary level to ensure make a distinction between the important and the lesser one. At the same time, while ensuring that the main model is in accordance with the requirement, it should also meet the requirement of the public and the accurate relation between the important and common type should also be guaranteed. Moreover, the relation among different modes, basic infrastructure, basic research, and the relation between model research and advanced model should be taken into consideration. No matter the relation among different models or the relation between basic infrastructure and basic research, they have big effects. For basic research, it does not only study on the aviation scientific research but also can accumulate extensive experience which can help to avoid faults in the following. Therefore, it will bring along with obvious effects and can greatly improve the development of aviation research and technology. The advanced research and research model are mainly concerned for personnel allocation because only by reasonable and scientific allocation, can we perfectly carry out research on aviation enterprises and avoid improper personnel allocation with unprofessional employees and uneven working hours. In addition, the relation determination of advanced research and research model can help employees to make detailed and scientific allocation, which can encourage different employees to make careful work and take clear responsibilities.

\section{B. Secondly, relationship determination between important and difficult tasks}

There should be a good plan for the aviation scientific research and production management which is the key because it can guarantee the smooth operation. Therefore, for research plans, we have to make reasonable and scientific plans which should not only take the ability of enterprises into consideration but also cannot exaggerate plans with reasonable understanding to highlight the hierarchy of the overall plan. Comprehensive considerations can guarantee the reasonable scientific research and production in aviation enterprises to avoid waste of impertinent cost, which can also clear the important and key points in different stages to determine required technology. Scientific research and production in aviation enterprises are serious projects, which need scientific planning. For the overall scientific and research work we have to highlight the key points and consider the difficult task while clearing important tasks and the relation between them so as to carry out reasonable classification. For the important and difficult tasks occurring in different layers, we have to analyze and understand so as to quickly solve these problems.

\section{Thirdly, the relation among important, difficult tasks and human resources}

For aviation enterprises, there will be a glittering array of important and difficult points in the course of researching. Concerning the shortage of effective human resource nowadays, we have to deal with the relation between human resources and tasks. Only by reasonably taking advantage of human resources can we avoid the nervous pressure. In addition, staffs should carry out mutual discussion and the experience analysis on the technology is not only mutual communication but also can improve the technology level and the personnel ability. What's more, for the scientific research in aviation enterprise, we have to integrate talents for important and difficult tasks in different stages which cannot only help to solve tasks but also carry out mutual discussion to achieve complementary effect. Furthermore, the important and difficult tasks, talents requirement and the relation between both of them should be properly dealt with. While carrying out scientific research work, we should also pay attention to cultivate talents and expand talents so as to guarantee that the relation between the important and difficult tasks as well as talents is reasonable.

\section{INFORMATIZATION CONSTRUCTION OF SCIENTIFIC RESEARCH AND PRODUCTION MANAGEMENT}

At present, the world is informational and anyone cannot be separate from information, including the scientific research and production management in aviation enterprises, and informatization construction. We should perfect the aviation scientific research and production, which can strengthen the competence and bring along with quicker development for aviation enterprises.

For aviation enterprises management, there are countless problems in the informatization construction. To begin with, the advanced information technology can not be fully integrated into the aviation enterprise management; secondly, the information sharing does not have good effect, namely, information isolated island; thirdly, concerning informatization construction, there are various problems in top-level design and there is only strong demand for urgent management which will lead to irrationality. The appearance of these problems showing that there are demerits in aviation scientific research and production management, including problems in terms of rationality, science and system which demonstrate the uneven management level; in the course of scientific research and production, the supervision as well as the 
implementation of the whole process lags behind; the simultaneous operation of different models, the communication and understanding cannot be fulfilled; the elements occurring in the projects cannot be highlighted in the management.

We have to comprehensively understand the above problems and informatization construction so as to fully apply informatization into aviation enterprises' scientific production and establish an information integration platform. The platform shall lead to obvious effect and cannot only promote consolidated operation of different models to realize goals and at the same time improve the controlling ability of same models so as to improve the overall ability of scientific research and production management to comprehensively integrate labor, finance, material resources and information to finally guarantee the smooth implementation of production.

The informatization construction for scientific research and production management mainly includes the following optimization and controlling: Firstly, for the workflow and management system, the scientific research and production management in aviation enterprises should establish a perfect information system step by step so as to guarantee its sophistication and rationality to promote the management development. In the past, it paid attention to the overall process, including a plenty of management, such as plan management, contract management, quality reliability management. The scientific research and production management can gradually perfect the single model management which can provide powerful guarantee for its meticulous management. Along with the advance and development of society, we have to manage the single model and at the same time, there is a higher requirement on various projects management which needs s unified philosophy. For current enterprises, they have to take the cycle, quality guarantee in the scientific research into consideration so as to guarantee its regulation, reasonableness, and scientific planning. Concerning these problems, we have to carry out detailed division and simplify the complicated as well as difficult problems. Besides, for simple questions a process-oriented plan is needed to change the process issue into informationization issues. Secondly, adopt information system integration and take the real condition of aviation enterprises' production management into consideration. If there are different procedures and different platforms, enterprises have to carry out information communication because the function of information integration is irreplaceable. Thirdly, strengthening the informmationization construction and management should firstly consider and face the condition that there might be difficult and complicated issues which cannot be quickly completed. What's more, along with the advance and development of the society, the technology is constantly updating and developing which constantly push the change and transfer of the scientific research and production management in aviation enterprises. Therefore, we have to perfect and advance the management process. Finally, we have to face the actual conditions we are going to face in the scientific research and production management. By continuous confirmation and planning, we can gradually perfect the informatization construction so as to make great contributions.

\section{UNCERTAINTY QUANTIFICATION OF SCIENTIFIC RESEARCH AND PRODUCTION MANAGEMENT}

The optimization and controlling for the scientific research and production management in aviation enterprises should take the uncertain information analysis into consideration. The quantitative analysis cannot acquire information because there is a glittering array of unknown matters which shall ignite a plenty of uncertain information in the course of scientific research and production management, which can be divided into three categories: random information, fuzzy information, and grey information. Random information refers to the unknown; grey information refers to the subjective unknown for objective things while fuzzy information refers to the objective unknown for objective matters. Concerning these unknown issues, we have to carry out quantitative processing so as to provide guarantee and basis for the scientific research and production management. In concrete, we can adopt the following methods:

\section{A. Fuzzy Mathematics Method}

There is no boundary definition for fuzzy matters and the fuzzy mathematics methods can play a special role and its features show as follows: for different fuzzy matters, we can carry out quantitative analysis so as to perfect the plan; analyze all possible elements to guarantee that there will be more choices in the course of scientific research and production management; integrate its accuracy, fuzzy characteristic, which shall ignite obvious function.

\section{B. Grey System Model Method}

Grey system model method summarizes the black-box theory to replace uncertain information. In the whole process of scientific research and production management, there will be a glittering array of uncertain matters, including planning, process, result, etc which can be conclude as grey system and can be used to find out the rules to seek for their similarities and quantify these uncertain data.

\section{Probability theory and Mathematical Statistics Method}

There is a smart chance for randomness which shall lead to uncertain issues. By probability theory and mathematic statistics method, we can carry out a further analysis and have further understandings on the rules of the randomness. Based on this, we can have a unified analysis and understanding on random matters and its effect shall be full played with quantitative processing.

\section{CONCLUSION}

Nowadays, the scientific research and production management in aviation enterprises can be beckoned as an important task, which needs further optimization and 
controlling so as to guarantee that it will be taken full advantage of. By level production, informatization construction and the quantitative processing for the uncertain issues, we can prefect its management and further optimize and control it so as to ensure that it will be developed greatly with more values.

\section{ACKNOWLEDGMENT}

The work is supported by the Aviation Foundation (2013ZG54034).

\section{REFERENCES}

[1] Renchong. Cultural perplexity and innovation of aviation enterprises [J]. Ideological and political research. 2002(08)

[2] New aviation business partners[J]. Aeronautical Manufacturing Technology. 2007(07)

[3] Feng Mei, Jiang Yanqing. Brief discuss on the social responsibility of
Chinese aviation enterprises [J].Chinese Market. 2009(28)

[4] Yi Zhibin, Lin Gengyuan, Li Zhongshou, Wang Guocheng. Worries and Countermeasures about the loss of aviation enterprise technology[J]. Aeronautical Engineering. 1995(01)

[5] Liu Guanglin. Accelerate and improve the aviation competence [J]. Aerospace Science and Technology. 2002(06)

[6] Jiang Zhen, Xu Rendong. Implement 9100 standard and perfect the quality management system establishment of aviation enterprises [J]. Aeronautic Standardization. 2009(01)

[7] Zuo Hugang. Study on the maintenance cost of modern aviation enterprises [J]. China Management Informationization. 2011(21)

[8] Fan Jin. Eight promotion strategies to promote the aviation enterprise market sales[J]. Air Transport \& Business. 2013(07)

[9] Li Jian, Li Huilan. Explore on the aviation enterprise management model [J]. Journal of Zhengzhou Institute of Aeronautical Industry Management.1995 (02)

[10] Li Jian, Li Huilan. Explore on the aviation enterprise management model [J]. Journal of Zhengzhou Institute of Aeronautical Industry Management.1995 (02) 